\title{
CARTOGRAFANDO INDIVÍDUOS DO PASSADO COLONIAL: O USO DO HISTORICAL GIS NA RECONSTITUIÇÃO DA DISTRIBUIÇÃO POPULACIONAL NO PARANÁ TRADICIONAL (1765-1830)
}

Leonardo Brandão Barleta Orientação: Maria Luiza Andreazza e Martha Daisson Hameister

PALAVRAS-CHAVE: Paraná tradicional; Historical GIS; listas nominativas.

Colocar os problemas humanos de tal modo que uma geografia humana inteligente os veja dispostos no espaço e, se possível, cartografados: sim, sem dúvida, mas colocá-los não somente no presente e para o presente, colocá-los no passado, torná-los parte do tempo; deslocar a geografia de sua busca das realidades atuais, à qual ela exclusivamente - ou quase se aplica, persuadi-la a repensar, com seus métodos e seu espírito, as realidades passadas e, nesse caminho, o que se poderia chamar os futuros da história ${ }^{1}$.

O estudo que ora se apresenta é resultado do desdobramento de um projeto de Iniciação Científica ${ }^{2}$ que deve ser entendido sob o prisma da multidisciplinariedade, tanto no âmbito teórico, quanto no metodológico. Buscamos aqui colocar a história em diálogo com outros saberes (geografia, cartografia, estatística, demografia, informática) frente ao problema de criar modelos de análise e de representação da distribuição e organização espacial dos indivíduos no passado colonial brasileiro. Mais especificamente, cartografar a dispersão das populações arroladas nas listas nominativas de habitantes da capitania de São Paulo referentes ao Paraná tradicional, na passagem do Setecentos para o Oitocentos.

\footnotetext{
${ }^{1}$ BRAUDEL apud LIRA, Larissa Alves de. Fernand Braudel e Vidal de La Blache: Geohistória e História da Geografia. Confins [Online], v. 2, 2008, http://confins.revues.org/index2592.html, Acesso em 17/11/2009.

${ }^{2}$ Financiado pelo CNPq no período de agosto/2008 a julho/2009, sob orientação da professora Maria Luiza Andreazza e se inseriu no interior de seu projeto Mobilidade populacional e redes sociais em Santo Antonio da Lapa e nos sertões de Curitiba na segunda metade do século XVIII.
} 
A própria formulação desta questão central revela a interseção - no ponto de vista teórico - de conceitos que, por definição, caracterizam as disciplinas que sustentam este estudo: a história $\left(\right.$ tempo $\left.^{3}\right)$ e a geografia (espaço ${ }^{4}$ ). Este tipo de preocupação já se encontra presente em outros trabalhos, como $O$ Mediterrâneo, de Fernand Braudel. Nele, o protagonista da história que se desenrola é o próprio espaço, numa relação com a longa duração, onde as estruturas sociais ganham expressão territorial.

Entretanto, neste trabalho o recorte de tempo é bem mais limitado, estando associado a uma conjuntura específica do Império Português e não à longa duração. $\mathrm{O}$ espaço aparece relacionado a população que nele habita, expressa nas listas nominativas de habitantes, também conhecidas por maços populacionais. Essas fontes são constituídas por censos de habitantes estabelecidos em determinado território, realizado pelas companhias de ordenança a partir da segunda metade do século XVIII. Constituiu importante instrumento para a administração lusa, proporcionando maior conhecimento sobre o território, os súditos, seu potencial militar e econômico. A coleção trabalhada nesta monografia se encontra no Arquivo Público de São Paulo, com cópias no Centro de Documentação e Pesquisa de História dos Domínios Portugueses (CEDOPE/DEHIS).

Na capitania de São Paulo, esta documentação passará a ser produzida - definindo, assim, o início do recorte temporal deste projeto - quando da chegada de D. Luis Antônio de Souza Botelho e Mourão (o Morgado de Mateus) na condição de governador e capitãogeneral, em 1765. Este período é acalorado pelas guerras entre

\footnotetext{
${ }^{3}$ Refiro-me em especial a definição proposta por Marc Bloch, da história enquanto "uma ciências dos homens no tempo". Cf. BLOCH, Marc. Apologia da História, ou,O ofício do historiador. Rio de Janeiro: Jorge Zahar Ed., 2001, pp. 51-68.

${ }^{4}$ Conceito este entendido como "formado por um conjunto indissociável, solidário e também contraditório, de sistemas de objetos e sistemas de ações, não considerados isoladamente, mas como o quadro único no qual a história se dá”, cf. SANTOS, Milton. A Natureza do Espaço: técnica e tempo, razão e emoção. São Paulo: Editora da Universidade de São Paulo, 2006, p. 39.
} 
portugueses e espanhóis ao sul da colônia e pelo malogro de tratados de limites que buscavam dar conta desta questão (como o Tratado de Madri - 1750; El Pardo - 1761; Paris - 1763). Por outro lado, a situação interna da própria capitania não satisfazia o novo governador, que em várias correspondências narrava

o quadro de decadência e abandono das terras paulistas e, sobretudo, de sua população, bastarda, mameluca, inculta, enfermiça, não adaptada ao trabalho sistemático e ao aproveitamento de novidades como o arado, introduzido aqui pelo governado ${ }^{5}$.

Diante deste cenário, o governo de Morgado de Mateus introduz políticas ilustradas, seguindo diretrizes definidas pelo Marquês de Pombal, reformando a administração colonial lusa. Observa-se o desenvolvimento de novas ferramentas voltadas a gestão do território, com acentuado cunho estatístico ${ }^{6}$ - como as listas nominativas, ocupadas com a produção de informações sobre a população da capitania.

Num primeiro momento, estes censos estarão diretamente relacionados com interesses de guerra, avaliando o potencial militar daquela população e auxiliando no recrutamento de novos soldados. Com o passar dos anos, ainda mesmo na própria gestão de D. Luis Antônio de Souza (que vai até 1775), estas listas passam a acentuar também preocupações econômicas e populacionais. A partir de 1776, homens e mulheres passam a figurar nesta documentação, bem como aumenta consideravelmente a quantidade de dados extraídos sobre a população. Sob o reinado de D. Maria I, em 1797, são inseridas importantes alterações na confecção das listas, tais como a

\footnotetext{
${ }^{5}$ TORRÃO FILHO, Amilcar . O 'milagre da onipotência' e a dispersão dos vadios: política urbanizadora e civilizadora em São Paulo na administração do morgado de Mateus (1765-1775). Estudos Ibero-Americanos, Porto Alegre, v. XXXI, n. 1, 2005, p. 149.

${ }^{6}$ Maria Luiza Marcílio define está fase com proto-estatístico, do começo da produção das listas nominativas (1765) até o primeiro censo nacional (1872), cf. MARCÍLIO. Maria Luiza. Crescimento demográfico e evolução agrária paulista, 1700-1836. São Paulo: Hucitec, EDUSC, 2000, pp. 31-33.
} 
padronização das informações para todo o território luso a partir de um modelo enviado a cada capitão, além de incluir questões relativas a produção, exportação, importação e consumo.

O recorte temporal abordado neste estudo se estende até 1830, fase em que inicia a desorganização na confecção destes recenseamentos. A quantidade de listas passa a ser rarefeita, desigual na distribuição espacial e relapsa na coleta das informações. Desta forma, as balizas temporais são estabelecidas com base na homogeneidade (ainda que num sentido de crescimento e complexificação) das informações disponibilizadas nas fontes, do início de produção das listas (1765) até o começo de sua desorganização (1830).

O espaço é o Paraná, mas não necessariamente a circunscrição administrativa emancipada de 1853; é o "Paraná meridional da criação de gado, das invernadas, do tropeirismo, do mate e da madeira”," “o Paraná mais 'antigo', 'tradicional', cuja história confunde-se com o início do povoamento que se verificou sobre a égide do poder colonial português" ${ }^{\text {. }}$. No período, esta região se encontrava na circunscrição administrativa da capitania de São Paulo. No entanto, na passagem do Seiscentos para o Setecentos, já dava "início da definição de uma identidade regional, fundada na pecuária”". São os campos Gerais e de Curitiba, que ‘futuramente’ se estenderão a Guarapuava e Palmas (embora aqui não sejam abordados), regiões adjacentes à Serra do Mar que se estendem sertão afora.

A inflexão entre as categorias de espaço e tempo levam, também, à discussão multidisciplinar do ponto de visto metodológico. O problema posto, de "cartografar" as populações do Paraná tradicional, percorreu caminhos não muito comuns aos historiadores. Tornou-se necessário, no desenvolvimento deste estudo, a

7 NADALIN, Sérgio Odilon. Paraná: ocupação do território, populações e migrações. Curitiba: SEED, 2001, p. 8.

${ }^{8}$ Idem, ibidem, p. 20.

${ }^{9}$ Idem, ibidem, p. 44. 
aproximação com métodos e técnicas de outros campos. Destaca-se o uso do geoprocessamento e, mais especificamente, o GIS (Geographic Information System), tecnologias que consistem em um conjunto de conceitos, métodos e técnicas para tratamento de informação geográfica. Estas recentemente vêm ganhando impulso em análises no campo historiográfico ${ }^{10}$, sob o nome de Historical GIS, que a partir da inserção da variável tempo, permite observar as transformações históricas (ou seja, ao longo do tempo) ocorridas no espaço.

Entretanto, a ferramenta sozinha não resolve os problemas específicos da pesquisa e, assim, adequações para o uso com as listas nominativas tiveram que ser gerados durante a investigação, para que o uso do recurso pudesse apresentar seus efeitos. A quase inexistência de bibliografia sobre o assunto - talvez por ser nova e pouco utilizada nos estudos históricos - e mesmo sobre métodos apropriados para a resolução dos problemas específicos da pesquisa exigiu a produção de uma nova metodologia para a construção de bases cartográficas que analisem e representem os traços da população em questão. Nota-se que tal tipo de trabalho jamais foi realizado a partir de listas nominativas de habitantes, tornando necessário que a metodologia proposta levasse em consideração as questões particulares colocadas por este corpo documental.

Houve a necessidade de se fazer a escolha de algumas entre as muitas informações oferecidas nas listas nominativas: os valores totais de população, classificados por sexo e por condição jurídica (livre e escravo). Essa seleção justifica-se por estarem sempre presentes nas listas consultadas, ainda que, por vezes, fossem obtidos indiretamente. Cabe ressaltar ainda que o caráter experimental deste projeto exigiu que a sorte dos dados analisados coubesse no tempo restrito de pesquisa, para a obtenção de resultados consistentes. Como forma de viabilizar a execução o projeto no tempo previsto, a

\footnotetext{
${ }^{10}$ Cf. GREGORY, Ian; HEALEY, Richard. Historical GIS: structuring, mapping and analysing geographies of the past. Progress in Human Geography, v. 31(5), 2007, pp. 638-653.
} 
pesquisa se focou em amostragens decenais (ou próximos a isso) nas listas analisadas ${ }^{11}$.

Em posse destes indicadores, voltaram-se as atenções para o trabalho com o GIS. Segundo Gregory, esta tecnologia pode ser entendida como um banco de dados espacialmente referenciado, uma ferramenta de análise e um instrumento de visualização destes dados $^{12}$. Num plano espacial, é possível referenciar a partir de sistemas de coordenadas geográficas objetos, sejam eles pontos, linhas, polígonos ou imagens, associando a cada um deles atributos pertinentes ao estudo. A partir destes dados, o GIS permite a exploração, investigação, análise e representação gráfica com uso de diversos métodos e conceitos.

Ainda que haja trabalhos de natureza semelhante para recortes espaciais e cronológicos diferentes ${ }^{13}$, esses estudos apresentam problemas distintos aos colocados neste projeto. A representação do espaço é feita através de polígonos, isto é, áreas com limites bem definidos para identificar os espaços analisados. Sobre esses objetos, é estipulada uma escala de cores para cada faixa de população, que se contrastam, e formam uma representação da distribuição dos indivíduos no espaço em questão. A metodologia aqui apresentada considera, contudo, que para o Paraná tradicional no período estudado, há a impossibilidade de definir áreas precisas que delimitem cada espaço, por não serem claramente definidos os limites das jurisdições ou mesmo estas sobrepostas. Ainda mais além, uma

${ }^{11}$ Eles são: 1765, 1776, 1786, 1796, 1806, 1815, 1824, 1830, e alguns exemplos se encontram no final do texto, com uma formatação reduzida.

${ }^{12}$ GREGORY, Ian. A place in History: a guide to using GIS in historical research. Essex: Arts and Humanities Data Service, University of Essex, 2002, disponível online em http://www.ahds.ac.uk/history/creating/guides/gis/index.html, acesso em 25/11/2009.

${ }^{13}$ BASSANEZI, Maria Silvia C Beozzo; SCOTT, Ana Silvia Volpi; BACELLAR, Carlos de Almeida Prado; TRUZZI, Oswaldo Mario S. Atlas da Imigração Internacional em São Paulo, 1850-1950. São Paulo: Editora da UNESP, 2008; GIS for History. The First Census: America in 1790. Online: http://www.gisforhistory.org/projects/firstcensus_st/, Acesso em 25/11/2009. 
reflexão aprofundada acerca dos comportamentos sociais do período estudado e sua relação com o espaço leva a considerar que a apreensão da espacialidade (e, conseqüentemente, a atuação dos sujeitos sobre o meio) parte uma referência pontual: a igreja matriz, a capela, a fortaleza, etc ${ }^{14}$.

Desta forma, como opção tanto teórica como metodológica, atribuiu-se a cada localidade encontrada nas listas nominativas um ponto, o qual foi vinculado aos valores totais da população, classificados por sexo e por condição jurídica resultantes da fase de contagem e coleta de informações. Assim estruturou-se uma base de dados espacialmente referenciada do Paraná tradicional e sua população.

A metodologia proposta por este trabalho se concretiza, enfim, na aplicação de um cálculo estatístico de estimação de padrões densidade para eventos pontuais, denominado "método de kernel". Com este processo, busca-se produzir um efeito de "dispersão" característico das populações daquele período a partir da construção de um modelo que estipula a densidade em cada ponto do plano levando em consideração a proximidade e a intensidade dos vizinhos. Isto é, as regiões com mais população e/ou número de localidades maior recebe um índice kernel superior às localidades isoladas e com pouca população. Em posse destes índices, é criada uma representação, que distribui estes valores a partir de escalas de cores, sendo as tonalidades mais escuras usadas para representar as regiões com população mais densa.

O resultado final deste trabalho é acompanhado por um conjunto de quarenta e seis mapas gerados pela metodologia desenvolvida. Produziu-se, então, uma proposta de modelo de distribuição e dispersão dos indivíduos num espaço colonial inserido num intenso processo de transformação, tanto em termos das

14 O espaço poligonal, por outro lado, é posterior e pode associado ao desenvolvimento do capitalismo e da burguesia, cf. SANTOS, Douglas. A reinvenção do espaço: diálogos em torno da construção do significado de uma categoria. São Paulo: Editora UNESP, 2002, p. 29. 
dinâmicas de ocupação territorial como das formas de controle da administração lusa sobre essa população. Estes mapas permitem interpretar espaços tais como áreas de fronteira em expansão e, em menor monta, o potencial de produção comercial.

Para além dos próprios mapas, o desenvolvimento deste trabalho com a ambição de multidisciplinariedade permitiu a criação de uma nova metodologia que lança outros olhares sob uma fonte já clássica para os estudos de população, demografia histórica, etc. O diálogo com a geografia, a cartografia, a estatística, a demografia e a informática se mostrou benéfica a história, na medida em que sua execução amplia o instrumental (teórico e metodológico) disponível ao historiador para a resolução de seus problemas, oferecendo outros mecanismos de análise e discurso sobre os homens no tempo.

Como palavras finais, manifesta-se aqui a continuidade desta investigação a partir do refinamento da metodologia apresentada e da ampliação em outros corpi documentais. A função kernel utilizada se mostrou eficiente para neste estudo, entretanto a adaptação as especificidades do período, do espaço e das fontes que fazem parte da pesquisa permitirá a complexificação do resultado final, como, por exemplo, a variabilidade da dispersão em diferentes localidades. Ainda, tal continuidade também se manifesta na inclusão de novas variáveis obtidas a partir das listas nominativas, como faixas etárias, cor, produção, etc. Também já se realizam alguns testes para sua aplicabilidade sobre dados colhidos em outras fontes, tais como os róis de confessados, registros batismais, de casamento e óbito, relatos de "descobridores de caminhos", cartas de sesmaria, pólos de comercialização de produtos coloniais, datas e registros de terras, evidências arqueológicas, etc. A intenção é gerar também para essas fontes já clássicas em estudos históricos metodologias que instrumentem novas perspectivas de análise que conjuguem espaço, tempo e recursos para a sua visualização. 
Revista Vernáculo, n. 23 e 24, 2009
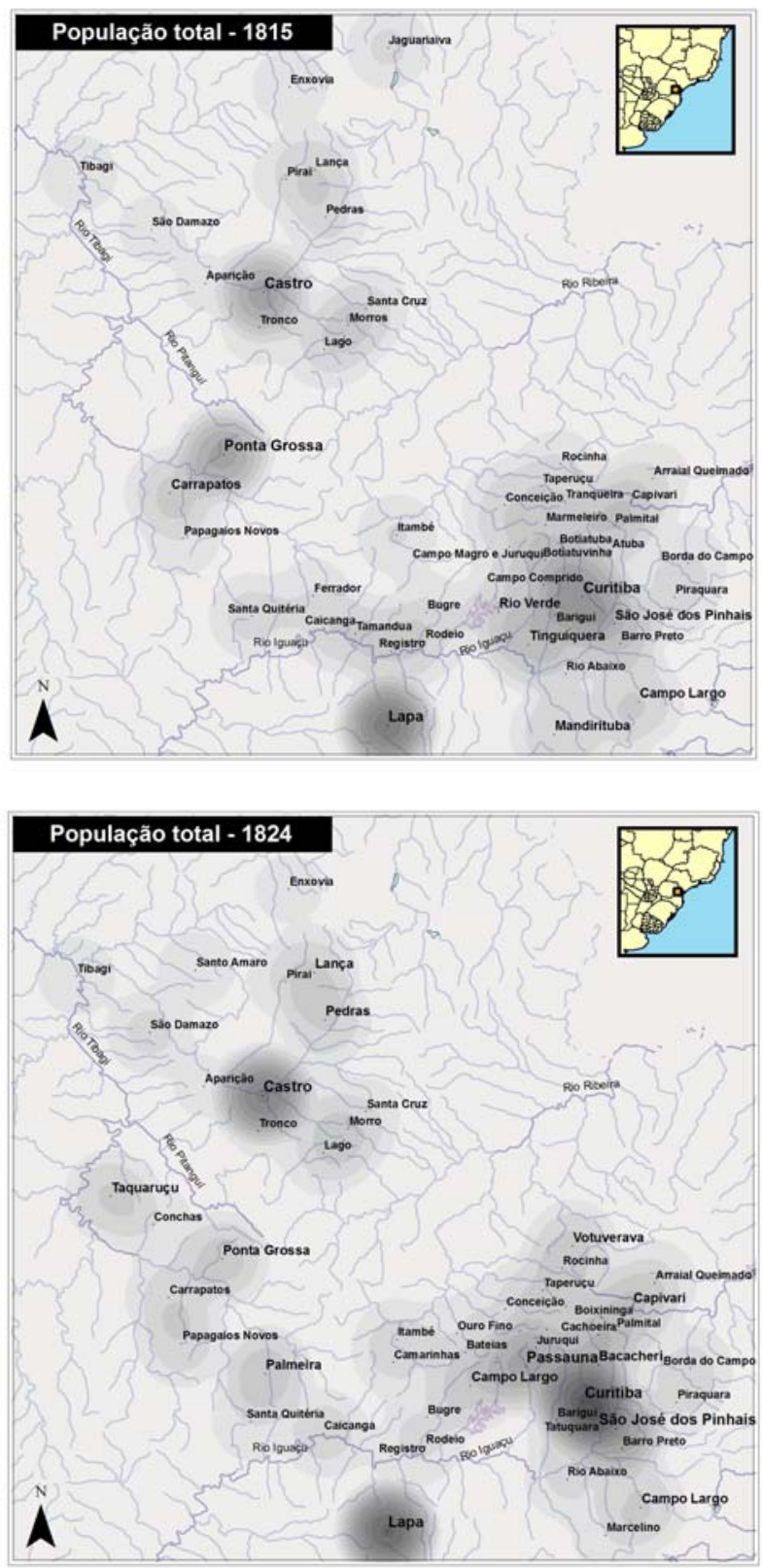
Revista Vernáculo, n. 23 e 24, 2009

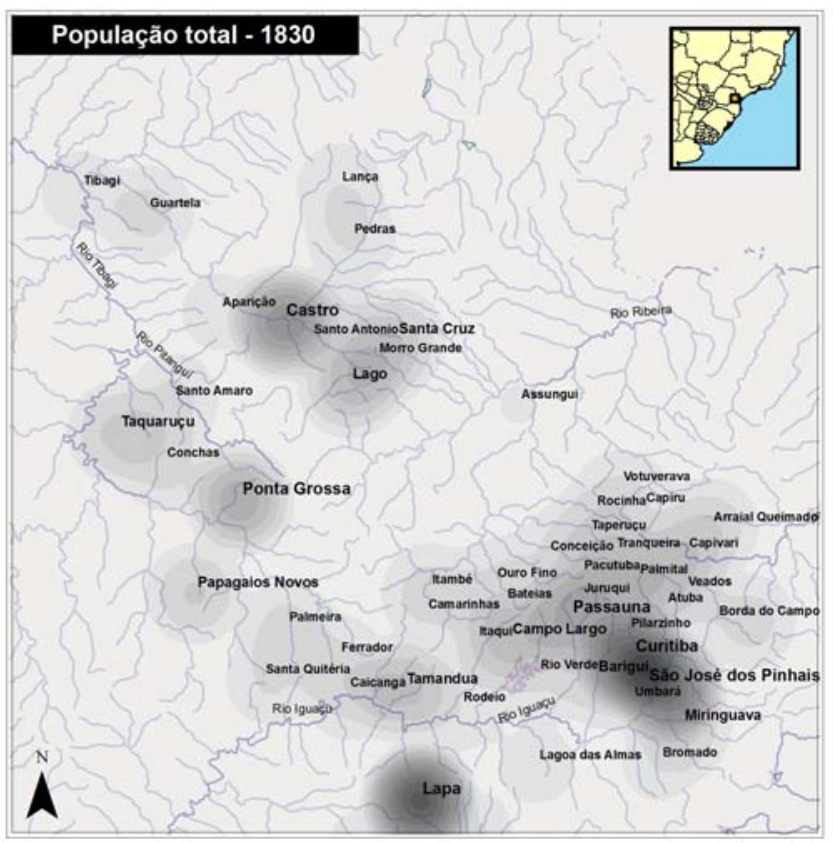

